\title{
A Review on Development of Stair Case Ramp
}

\author{
Shailesh Shinde ${ }^{1}$, Rupesh lonare ${ }^{2}$, Ram Sahariya ${ }^{3}$, Prashant Pagare ${ }^{4}$, \\ Mayur Dangore ${ }^{5}$, Rakshit Walke ${ }^{6}$, Shubham Wanjari ${ }^{7}$, Amol Sawlikar $^{8}$ \\ ${ }^{12345678}$ UG Students, Department of Mechanical Engineering, NIT, Nagpur, India
}

Received on: 15 May, 2021, Revised on: 17 June, 2021, Published on: 19 June, 2021

\begin{abstract}
The objective of this paper is to enlighten the ways of development of the staircase ramp. We know that the handicapped people goes through the difficulty when they want to travel or move from one floor to another. They took the support of the other person for the movement. Sometimes it more difficult, when the person is with the wheel chair. Our approach is to develop the staircase ramp for the disabled people who can move from one floor to another without any support of the other person. The cost effectiveness of the ramp must be there. So we have gone through various literature reviews to search for the development of the stair ramp. We have developed the approach that can help the people to nove from one floor to another floor without any other support.
\end{abstract}

Keywords- Stair Lift, Comfort, Mobility Problems, Escalators, Traditional Ladders

\section{I- INTRODUCTION}

$\mathbf{T}$ here are many old and physically disable peoples in the world and it is difficult for them to climb stairs as compared to normal persons. So to help them and to help the persons who cannot afford lift as their houses are small, the project is made. The most concern of this project is to fabricate a mechanism which will lift them up and put them down whenever they want and at very low budget. A stair with escalator is a mechanical device for lifting people up \& down. Rail is mounted on the stairs on which a platform is attached. The platform is lifted by a simple mechanism of rope \& pulley by it is lifted. Person gets on the platform is lifted when he/she switch on the plug the motor starts, after that the shaft of motor is connected to gearbox (speed reducer) by the Oldham's coupling. The outlet shaft of gearbox is connected to another Oldham's coupling which transmits the power to the spindle to wind or unwind the rope. Winding the rope will lift the platform up \& unwinding will make the platform go down.

Advancements in technology made disabled people to lead an independent life and play a more productive role in society. Stairways into buildings present a significant environmental barrier for those with mobility impairments, including older adults. A number of home access solutions that allow users to safely enter and exit the home exist, however these all have some limitations. The purpose of this work was to develop a novel, an inclusive home access solution that integrates a staircase and a lift into one device. The Excel stairway lift system will be installed in order to give people the independence needed to move around their home. The use of two individual stairway lift systems ensures that she can easily move from level to level. A handle placed in between the two stairway lift systems, which will allow them to move from one chair to the other. A novel remote centre mechanism was proposed where in a wheelchair can glide along the stairs. In this system, the angle of the seat on the attitude of the chair changes along the angle of inclination of the user irrelevant of the angle of the wheelchair. An attitude sensor along with a relatively small actuator used, this minimal degree of active control made possible. Usually we find that people neither can drive wheelchairs properly at cross muddy patches nor uneven terrain. Similar is in the case of stair where one approach is use of legs. Advances in robotics have made it possible to build and control machines in every way possible. It is not difficult to build a wheelchair with legs that can climb slopes, step over obstacles, which run along stairs. In 1987 a four legged chair developed by the University of Illinois at Chicago and the Veterans Administration Hines Rehabilitation Research and Development Centre based 


\section{International Journal of Innovations in Engineering and Science, www.ijies.net}

on research in quadruped walking was developed. This invention could sustain a weight of around $110 \mathrm{~kg}$. In addition, has a capacity of carrying a payload of 113.6 $\mathrm{kg}$.

\section{II -PROBLEM STATEMENT \& OBJECTIVES}

\subsection{Problem Statement}

There exist few models such as escalators and elevators, used to go up and down the stairs but these, are not explicitly for the physically handicapped. For an instance, a physically handicapped people cannot use the escalator. There also exist scenarios where both elevators and escalators cannot be used due to limitations in architecture. Elevators occupy more space. Therefore, implementation in places, where sufficient space is not available, becomes tough. Healthy people develop the habit of depending upon elevators; therefore, physical activity reduces. In elevators, people get stuck for hours between floors when the power goes out and there is no back up for the power supply

\subsection{Objectives}

- The Main Objectives of this project is to develop an indoor as well as an outdoor stair lift.

- A Handicap person can stair without any support of another person.

- The middle class can be affordable.

- While going up and down the stair, safety is the primary.

\section{III - LITERATURE REVIEW}

Vanish V. Gaikwad, Previn S. Ghawde, Sandip J. Kadam [1] This topic deals with the fabrication and analysis of a stair case lift, which can be use as Material Handling System. In this system they use DC motor for changing the polarity of the power supply which will make the motor run in reverse direction connected with the earlier, while the later will form the entire assembly run to in downward direction, with the help of Toggle switches and push buttons. In this model they used MDF (Medium density fire core hard plywood) for making stair, and saddle. From ANSYS analysis it was found that for maximum load of $5 \mathrm{~kg}$ deformation is $0.0089403 \mathrm{~mm}$ with maximum stress $3.263 \mathrm{~N} / \mathrm{mm} 2$.

Prof B.B.Biswal [2] This project involves the design of an ergonomically designed electric wheelchair for domestic use by Indian old aged people. The product mainly consists of 3 modules viz. seat, links and frame.
The design is validated by developing Digital Mockups of individual parts are generated in CATIA and are assembled to form the final product. Necessary simulations of the product are generated in virtual environment of CATIA. Design Modification of ElectroPowered Chair with Staircase Climbing Ability (IJSRD/Vol. 6/Issue 01/2018/360) All rights reserved by www.ijsrd.com 1318

Weijun Tao, Junyi Xu and Tao Liu [3] In this article, a review of electric-powered wheelchair with stairclimbing current technology is given and its future tendency is discussed to inform electric-powered wheelchair with stairclimbing researchers in the development of more applicable and popular products. According to the author respective advantages and disadvantages of different types of electric-powered wheelchairs with stair-climbing are outlined for an overall comparison of the control method, cost of mechanical manufacture, energy consumption, and adaption to different stairs. Insights into the future direction of stability during stair-climbing are discussed as it is an important aspect common to all electricpowered wheelchairs with stair climbing. Finally, a summary of electric-powered wheelchairs with stairclimbing discussed in this article is provided.

A S Shriwaskar and S K Choudhary [4] This paper presents stair climbing mechanism by which chair will climb on stair without any assistance. Project revels about synthesis, modeling and simulation of mechanism for guiding wheels for climbing mechanism. Mechanisms like four bar mechanism, single slider crank mechanism, double slider crank mechanism, etc., are used for transmitting motion, force, torque, etc... Generally, a mechanism is designed for the desired performance output of the machine and these mechanisms are being used in case of climbing wheels. This project focuses on presenting the development of a stairclimbing wheelchair. This wheel chair is adaptable to climbing and descending stair and slopes. Operation on level ground is similar to the operation of a conventional wheel chair.

Murray J Lawn, Toshihide Sakai, Megumu Kuroiwa and Takakazu Ishimatsu [5] This paper focuses on presenting continued development of the "Nagasaki Stairclimber", A dual section tracked stairclimbing wheelchair "the Nagasaki Stairclimber" has been developed in Nagasaki, a dual section tracked wheelchair capable of negotiating the large number of twisting and irregular stairs typically encounted by the residents living on the slopes that 


\section{International Journal of Innovations in Engineering and Science, www.ijies.net}

surround the Nagasaki harbor. A control system has been added to the proven dual track mechanism wheelchair. The control system provides for automation. Recent developments include an auto guidance system, auto leveling of the chair angle and active control of the front rear track angle. Future work includes the continued development of the control system with regard to improved automation, safety and general robustness. Further refinement is also requiredon reducing the weight of system.

Harout Markarian [6] Wheelchair users face difficulties while crossing rugged terrains and sidewalks, as well as climbing up and down stairs. With the safety of the user as a main concern, the following concept will allow the occupant of the wheelchair to ascend and descend stairs while remaining safely on the seat. This conceptual design consists of two differential drive wheels and a two legged mechanism, in addition, it uses light weight material. Using Solidworks simulations, the dynamic analysis of the wheelchair is presented while it climbs the stairs. Finite element analysis is also performed on the wheelchair's frame, along with DC motor power analysis and control system design.

Mulik shriniwas, Salunkhe Rohit, Shaikh Shahrukh, Waghmode Dada, Swipnil Gaikwad [7] This article aims is developing a mechanism for easy transportation of heavy loads over uneven terrain. The need for such a system arises from day-to-day requirements in our society. Devices such as hand trolleys are used to relieve the stress of lifting while on flat ground; however, these devices usually fail when it comes to carrying the load over short height. Several designs were conceived that would allow a non-industrial hand trolley to travel over stairs, curbs, or uneven terrain while reducing the strain on the user. In our project the trolley is consisting the triwheel or tri-star mechanism eases the movement of trolley in irregular surfaces like holes, bumps, etc.

\subsection{Our Findings}

After going through all the research papers, we found that there is definitely some problem with everything. Most of those research papers have used chain drive, gear drive or some other mechanism, most of them used belt drive. we are using a different hi mechanism which is a lead screw mechanism this is our finding. This lead mechanism is being used. We don't know if a similar test has happened, we don't need it or we don't need to do it consistently, we'll just use it occasionally.

\section{IV- CONCLUSION}

The design of the wheelchair is compact and hence is able to move about in almost all the stairs that we find at institutions, offices, industries and also at some homes. The design is made very safe and there is no chance of failure of the frame and wheels under normal conditions According to the tests conducted, the stair climbing wheelchair has a capacity of carrying a load of $100 \mathrm{kgs}$ on flat surface. It has the ability to ascend a flight of stairs of 40-degree elevation carrying a weight of $55 \mathrm{kgs}$. The design of the wheelchair is compact and hence is able to move about in almost all the stairs that we find at institutions, offices, industries and also at some homes. The design is made very safe and there is no chance of failure of the frame and wheels under normal conditions.

\subsection{Future Scope}

The frame weight can be reduced by using high strength lightweight materials such as composites, carbon fiber. The wheelchair can be automated by using electronics so that it will automatically sense and climb the stairs.

\section{REFERENCE}

[1] Ruturaj Kulkarni, Bhumin Patel, "Design Of Stair Lift for curved path", International Journal of Current Engineering and Technology, P-ISSN 2347 - 5161

[2] Hüseyin R. BÖRKLÜ, “A Novel Conceptual Design of a Stair lift for Elderly and Disabled People”, Gazi University Articles.

[3] Wahyu sulistiyo, "Optimization of a stair lift design to realize a safe transportation system for the elderly and the disabled when using stairs", AIP Conference Proceeding.

[4] Nikhil Lokhande, "Development of stairs with accelerator", International Journal of Creative Research Thoughts, Volume 8, Issue 4 April 2020 | ISSN: 2320-2882

[5] V.N. Chougule, "Design and Structure Analysis of platform stair lift using finite element method ", IOSR Journal of Engineering, ISSN (p): 2278-8719 PP 10-17 